\title{
Ventolin Diskus and Inspyril Turbuhaler: An In Vitro Comparison
}

\author{
M.E.A.C. BROEDERS, M.D., Ph.D., ${ }^{1}$ J. MOLEMA, M.D., Ph.D., ${ }^{1}$ \\ P.K.P. BURNELL, B.Sc., M.Sc., Ph.D., ${ }^{2}$ and H.T.M. FOLGERING, M.D., Ph.D. ${ }^{1}$
}

\begin{abstract}
Dose delivery (total emitted dose, or TED) from dry powder inhalers (DPIs), pulmonary deposition, and the biological effects depend on drug formulation and device and patient characteristics. The aim of this study was to measure, in vitro, the relationship between parameters of inhalation profiles recorded from patients, the TED and fine particle mass (FPM) of Diskus and Turbuhaler inhalers. Inhalation profiles (IPs) of 25 patients, a representative sample of a wide range of $1500 \mathrm{IPs}$ generated by 10 stable asthmatics, $3 \times 16$ (mild/moderate/severe) COPD patients and 15 hospitalized patients with an exacerbation asthma or COPD, were selected for each device. These 25 IPs were input IPs for the Electronic Lung (a computerdriven inhalation simulator) to determine particle size distribution from Ventolin Diskus and Inspyril Turbuhaler. The TED and FPM of Diskus and FPM of Turbuhaler were affected by the peak inspiratory flow (PIF) and not by slope of the pressure-time curve, inhaled volume and inhalation time. This flow-dependency was more marked at lower flows (PIF $<40 \mathrm{~L} / \mathrm{min}$ ). Both the TED and FPM of Diskus were significantly higher as compared to those of the Turbuhaler [mean (SD) TED_diskus (\%label claim) 83.5 (13.9) vs. TED_turbuhaler (72.5 (11.1) $(p=$ 0.004), FPM_diskus (\%label claim) $36.8(9.8)$ vs FPM turbuhaler $(28.7(7.7)(p<0.05)]$. The TED and FPM of Diskus and FPM of Turbuhaler were affected by PIF, the flow-dependency being greater at PIF values below $40 \mathrm{~L} / \mathrm{min}$. Lower PIFs occurred more often when using Turbuhaler than Diskus, since Turbuhaler have a higher resistivity, requires substantially higher pressure in order to generate the same flow as Diskus. TED, dose consistency and the FPM were higher for Diskus as compared to Turbuhaler. The flow dependency of TED and FPM was substantially influenced by inhalation profiles when not only profiles of the usual outpatient population were included but also the real outliers from exacerbated patients.
\end{abstract}

Key words: dry powder inhaler, diskus, turbuhaler, electronic lung, fine particle mass

\section{INTRODUCTION}

$\mathbf{T}$ HE EFFICACY of inhaled drugs to the lungs includes three steps: dose delivery from the inhaler (total emitted dose, or TED) that results in a certain dose to patient, pulmonary deposition of the TED, and the biological effects of the dose. ${ }^{1}$

The TED and aerosolisation of drugs delivered by dry powder inhalers (DPIs) depend on its formulation, device characteristics (e.g., resistance to

\footnotetext{
${ }^{1}$ Department of Pulmonary Diseases, Dekkerswald, University of Nijmegen, Groesbeek, The Netherlands.

${ }^{2}$ GlaxoSmithKline Research \& Development Department, Ware, Hertfordshire, United Kingdom.
} 
airflow, or resistivity), airway characteristics and patient's inhalation technique. ${ }^{2}$ The inspiratory effort generates a negative pressure drop in the mouth. The mouth-pressure versus time curve was defined as the inhalation profile (IP). When the resistivity is known, the pressure profile can be converted into a flow profile. ${ }^{3}$ Peak inspiratory flow (PIF), ${ }^{4}$ slope of pressure versus time, ${ }^{5,6}$ inhaled volume $(\mathrm{Vi}),{ }^{1,7}$ and inhalation time $(\mathrm{Ti})^{8}$ are variables of the inhalation profile which may influence the TED.

Conventionally, the in vitro methods testing the TED and the fine particle mass (FPM) (the amount of drugs in the respirable range, $0.5-5$ $\mu \mathrm{m}^{9}$ ) are based on impaction on the Cascade Impactor tested at constant flows. These measurements played an important role in the development and optimalisation of inhalation devices. The relationship between in vitro and in vivo is still unclear. Most of the particle-size systems operate at constant and fixed flows (30,60 and 90 $\mathrm{L} / \mathrm{min}$ ) typically from a pump, which do not mimic the actual patients' IP.

In the present study, two multidose dry powder inhalers (DPI) were compared in vitro; the Inspyril Turbuhaler ${ }^{\circledR}$ (AstraZeneca, Sweden) contains 100 doses of $100 \mu \mathrm{g}$ salbutamol (spherical pellets) stored in a reservoir dosing unit, and the Ventolin Diskus ${ }^{\circledR}$ (or Accuhaler ${ }^{\circledR}$, GlaxoSmithKline, UK), which contains 60 individually sealed metered doses of $200 \mu \mathrm{g}$ salbutamol plus a lactose carrier.

A selection of typical "real life" inhalation profiles of patients with asthma and COPD with a wide range of bronchial obstruction was imported in a computer-driven inhalation simulator, the Electronic Lung (GlaxoSmithKline Research and Development Ware, UK). ${ }^{10}$ The purpose of this study was to measure the effects of the inhalation profile variables on the TED and FPM. Furthermore, differences of TED and FPM between the two devices were also assessed.

\section{MATERIALS AND METHODS}

\section{Study design}

In two previous studies, inhalation profiles were recorded with the Inhalation Profile Recorder ${ }^{11,12}$ (GSK R\&D Dept., Ware UK). In 10 stable asthma patients and three groups (mild, moderate and severe) of 16 COPD patients, 18 in- halation profiles were recorded for each device during six sessions over 10 weeks. Also, 15 hospitalized patients participated in a randomized study of inhalation profiles through placebo devices. ${ }^{13}$ For each device, triplicate inhalation profiles were recorded during day 1-9 of admission and in stable phase.

Twenty-five inhalation profiles with a wide range of characteristics were selected for Diskus and twenty-five inhalation profiles were selected for Turbuhaler from the total of 3000 profiles collected in these studies and were the input for the Electronic Lung ${ }^{10,14}$ (GlaxoSmithKline R\&D Dept., Ware UK), which enabled us to measure TED and the FPM.

\section{Materials used}

The study included the use of Ventolin Diskus inhaler, $200 \mu \mathrm{g} /$ dose (GlaxoSmithKline, UK) and the Inspyril Turbuhaler inhaler, $100 \mu \mathrm{g} /$ dose (AstraZeneca, Sweden).

\section{Inhalation profile}

The inhalation profiles (pressure vs time) were recorded by a pressure transducer: the inhalation profile recorder ${ }^{11}$ (GSK R\&D Dept., Ware UK). The transducer measured pressures in the mouthpiece during the inhalation through a placebo Diskus and Turbuhaler. The variables of the inhalation profile recorder are pressure slope [Slope] $(\mathrm{kPa} / \mathrm{sec})$, peak pressure drop [PPD] $(\mathrm{kPa})$, time to peak pressure drop: the time between the onset of the inhalation and the moment of reaching the PPD [Tp] (sec) (the start of the measuring time is the moment that the pressure passes the $0.2-\mathrm{kPa}$ threshold), peak inspiratory flow [PIF] (L/min), inhaled volume [Vi] (L) and inhalation time [Ti] (sec). The relationship between PIF and PPD was calculated ${ }^{3}$ by PPD $=$ PIF $\times R$, where $R$ is the resistivity of the device $\left[R_{\text {_diskus }}=0.02133(\mathrm{kPa})^{0.5}(\mathrm{~L} / \mathrm{min})^{-1}\right.$ and $R_{\text {_tur- }}$ buhaler $\left.=0.03223(\mathrm{kPa})^{0.5}(\mathrm{~L} / \mathrm{min})^{-1}\right] .{ }^{15}$

\section{Electronic lung}

The Electronic Lung is a computer-driven inhalation simulator ${ }^{14,16}$ (Fig. 1). In vivo IPS of patients were replicated. Next the mass and particle size distributions of drug delivered from a Ventolin Diskus and Turbuhaler were determined. The powder was drawn from the device into the metal sampling chamber by a computer- 


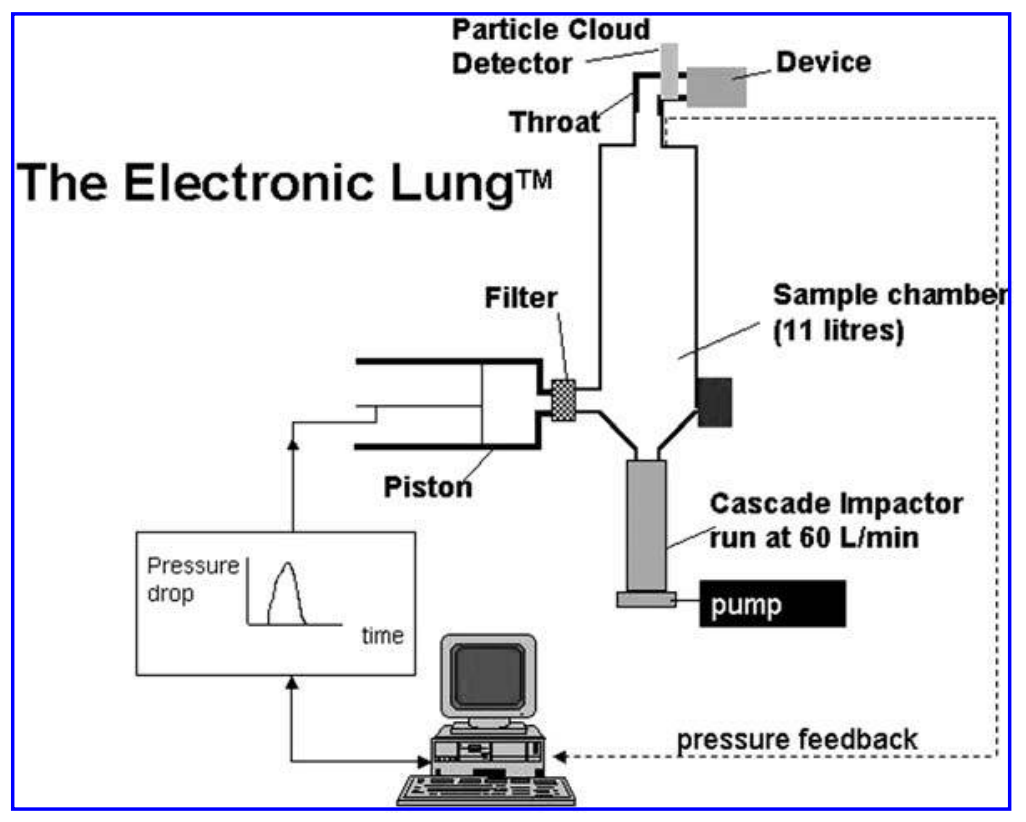

FIG. 1. The Electronic Lung.

driven piston, programmed by the IP. Then, the powder was extracted from the chamber by a second pump that was switched on after completion of the inhalation through an Anderson Cascade Impactor (Graseby Anderson Ltd, Orpington, UK) operating at $60 \mathrm{~L} / \mathrm{min}$. This was repeated 10 times to obtain a sufficient amount of drug for analyzing. The total emitted dose (TED) was the sum of the amounts of drug in the throat inlet, sampling chamber, and Cascade Impactor. The cumulative dose of the sampling chamber, throat, and the preseparator of the Cascade Impactor was labeled as coarse particle mass (CPM $>4.0$ $\mu \mathrm{m})$. The accumulated amount of drug on stages 1-5 of the Cascade Impactor represented the fine particle mass (FPM, 0.76-4.0 $\mu \mathrm{m}$ ), whereas the particles on stages 6 and 7 plus the filter were termed very fine particle mass (VFPM, <0.76 $\mu \mathrm{m})$.

The throat, sampling chamber, preseparator, and all stages were washed out with a suitable solvent. The TED, CPM, FPM, and VFPM were determined by high-performance liquid chromatography (HPLC).

\section{Statistical analysis}

SPSS for windows version 9.0 was used for calculating means of the inhalation parameters. Data were expressed as mean \pm SD. A $p$ value of $<0.05$ was considered significant.
To select the inhalation profiles which had to be a representation of the range of the different profiles generated in the study, it was assumed that the profiles were adequately described by PIF, slope, $\mathrm{Vi}$, and $\mathrm{Ti}$. These parameters were plotted in a four dimensional hypercube design. Four center inhalation profiles were selected to give a representation of the middle range. Points were taken as extreme if they were below the 25th percentile or above the 75th percentile. As far as possible the 16 combinations of the four factors: PIF; slope; Vi and $\mathrm{Ti}$ (each at two levels) were used to select the inhalation profiles that correspond to these design points. For each device five extra plots in the lowest peak flow range were selected. These selection of inhalation profiles gave the widest span of the data (not only of the usual outpatient population, but also outliers from the extremes of disease severity during exacerbation).

Regression models were fitted (using JMP statistical software) for TED, FPM as percentage of label claim and FPM as percentage of TED with the natural logarithm of PIF as an explanatory variable. Device differences were also investigated, as was the effect of TED on FPM.

\section{RESULTS}

A total of 1500 inhalation profiles through each device was recorded from asthmatics and 
COPD patients. For both Diskus and Turbuhaler, inhalation profiles of 25 patients were run with the Electronic Lung. The demographics of the patients from whom the selected inhalation profiles were taken, are shown in Table 1.

\section{Inhalation profile variables}

The mean inhalation profile variables are shown in Table 2. The PIF values of the Diskus were significantly higher as compared to Turbuhaler (mean [SD]: 100.1 [30.8] vs. 69.2 [19.3] $\mathrm{L} / \min [p<0.001])$. The inhalation time of Turbuhaler was significantly longer as compared to Diskus (mean [SD] 3.3 [1.3] vs. 2.5 [1.1] sec [ $p=$ $0.03])$.

\section{Effect of inhalation profile variables on total} emitted dose

Table 3 shows the Electronic Lung results (TED and FPM) for both devices.

Initially, the effect of PIF was assessed, since this is believed to be the most likely variable to influence the Electronic Lung results.

Figure 2 shows the relationship between TED and PIF. No significant correlation between PIF and TED was found for the Turbuhaler. Overall, the TED for Diskus was significantly higher than for Turbuhaler, but over a small increase in TED for Diskus, there appeared to be a slight flow dependency.
Effect of inhalation profile variables on fine particle mass

Figure 3 shows the FPM (percentage of label claim), plotted against PIF (L/min). There is a strong relationship between FPM and PIF, with FPM increasing as PIF increases. The rate of increase, however, appears to be greater when PIF is low.

Univariate regression models were fitted for TED as percentage of label claim, FPM as percentage of label claim, and FPM as percentage of TED with the $\operatorname{Ln}(\mathrm{PIF})$ as an explanatory variable.

Total emitted dose as percentage of label claim

$$
\begin{array}{cll}
\mathrm{TED}_{\text {_diskus }}=-54.6 & p=3.14 \mathrm{E}-07 & \mathrm{r}^{2}=0.57 \\
+30.4 \times \ln (\mathrm{PIF}) & & \\
\text { TED_turbuhaler }= & p=0.41 & \mathrm{r}^{2}=0.57 \\
54.9+4.2 \times \ln (\mathrm{PIF}) & &
\end{array}
$$

Fine particle mass as percentage of label claim

Ln(PIF) and TED both had statistically significant effects on FPM (percentage label claim).

\begin{tabular}{|c|c|c|c|c|}
\hline \multirow[b]{2}{*}{ Parameter } & \multicolumn{2}{|c|}{ Diskus } & \multicolumn{2}{|c|}{ Turbuhaler } \\
\hline & Mean (SD) & Range & Mean (SD) & Range \\
\hline Gender $(\mathrm{M} / \mathrm{F})$ & $17 / 8$ & & 14/11 & \\
\hline Age (years) & $66(9.2)$ & $34-75$ & $66(10.0)$ & $38-75$ \\
\hline $\mathrm{FEV}_{1} \% \mathrm{pr}(\%)$ & $63(22.1)$ & 24-106 & $66(26.7)$ & $16-105$ \\
\hline $\mathrm{FEV}_{1}(\mathrm{~L})$ & $1.7(0.7)$ & $0.7-3.3$ & $1.7(0.8)$ & $0.5-3.3$ \\
\hline $\mathrm{FEV}_{1} / \mathrm{VC}(\%)$ & $49(12.9)$ & $25-71$ & $50(16.6)$ & $22-82$ \\
\hline Reversibility (\%) & $8(6.6)$ & $2-30$ & $6(4.0)$ & $0-17$ \\
\hline Smoking: non/ex/current & $7 / 13 / 5$ & & $3 / 17 / 5$ & \\
\hline \multicolumn{5}{|l|}{ Device } \\
\hline DPI & 18 & & 18 & \\
\hline pMDI & 9 & & 9 & \\
\hline pMDI + spacer & 1 & & 4 & \\
\hline nebulizer & 1 & & 0 & \\
\hline
\end{tabular}
There was no additional contribution of the device type once these effects were accounted for.

$$
\begin{array}{rlr}
\mathrm{FPM}=-49.4+0.32 & p<0.0001 & \mathrm{r}^{2}=0.88 \\
\mathrm{TED}+13.1 \ln (\mathrm{PIF}) & &
\end{array}
$$

Table 1. Patient Characteristics

$\mathrm{FEV}_{1} \% \mathrm{pr}$, forced expiratory volume in $1 \mathrm{sec}$ as percentage of predicted; $\mathrm{FEV}_{1}$, forced expiratory volume in $1 \mathrm{sec}$; $\mathrm{FEV}_{1} / \mathrm{VC}, \mathrm{FEV}_{1} /$ vital capacity; reversibility, bronchodilator response of $\mathrm{FEV}_{1}(\%)$ related to the predicted value; device, device used by the patients in daily life. 
Table 2. Inhalation Profile Variables

\begin{tabular}{lcc}
\hline Mean (SD) [range] & Diskus & Turbuhaler \\
\hline PIF (L/min) & $100.1(30.8)[23.3-140.1]^{*}$ & $69.2(19.3)[22.1-98.8]$ \\
Slope $(\mathrm{kPa} / \mathrm{sec})$ & $13.2(8.0)[1.0-38.2]$ & $13.7(9.0)[0.9-32.8]$ \\
$\mathrm{Vi}(\mathrm{L})$ & $2.9(1.1)[1.0-5.3]$ & $2.8(1.4)[1.0-6.1]$ \\
Ti $(\mathrm{sec})$ & $2.5(1.1)[1.0-5.0]$ & $3.3(1.3)[1.1-5.8]^{*}$ \\
\hline
\end{tabular}

Mean inhalation profile variable: PIF, peak inspiratory flow; $\mathrm{Vi}$, inhaled volume; $\mathrm{Ti}$, inhalation Time. ${ }^{*} p<0.05$ differences between Diskus and Turbuhaler.

The effect of omitting the lowest PIF from the analysis

Recalculations of the fit without the lowest flows (PIF_diskus $23 \mathrm{~L} / \mathrm{min}$ and PIF_turbuhaler 22 $\mathrm{L} / \mathrm{min}$ ) were performed.

$$
\begin{array}{lll}
\text { TED_diskus }(\% \text { label } & p=0.002 & \mathrm{r}^{2}=0.51 \\
\text { claim })=-3.6+ & & \\
19.5 \times \ln (\mathrm{PIF}) & & \\
\text { TED_turbuhaler }(\% \text { label } & p=0.045 & \mathrm{r}^{2}=0.51 \\
\text { claim })=123.4- & & \\
11.8 \times \ln (\mathrm{PIF}) & & \\
\text { FPM }(\% \text { label claim })= & p<0.0001 & \mathrm{r}^{2}=0.80 \\
-48.6+0.32 \text { TED }+ & & \\
12.8 \times \ln (\mathrm{PIF}) & &
\end{array}
$$

The r-squared values for each of the two regression models are not significantly different, and there is no evidence that the model parameters change when the low flow data are omitted.

The residuals from these models have been plotted against the other inhalation profile variables (slope, Vi, and Ti). There was no indication for any other significant relationships.

\section{Differences between the two devices}

The Total Emitted Dose was significantly higher and marginally more variable overall for
Diskus than for Turbuhaler (83.5 [13.9] vs. 72.5 $[11.1] \%$ label claim, $p=0.004)$. There did not appear to be an effect due to device type at comparable inspiratory flows. The Turbuhaler having a higher resistivity, required substantially higher pressure, in order to generate the same flow at Diskus (Figs. 2 and 3).

\section{DISCUSSION}

The results of this study showed that the TED of Diskus was affected by the PIF, and no significant correlation between PIF and TED_turbuhaler was found. The FPM of Turbuhaler and Diskus were dependent of PIF and TED. These flow dependencies were more marked at the lower peak inspiratory flows (PIF $<40 \mathrm{~L} / \mathrm{min}$ ). Both the TED and FPM of Diskus were significantly higher as compared to Turbuhaler.

The aim of this study was to determine in vitro the drug delivery characteristics in respect of the

\begin{tabular}{|c|c|c|c|c|}
\hline \multirow[b]{2}{*}{ Parameter } & \multicolumn{2}{|c|}{ Ventolin Diskus } & \multicolumn{2}{|c|}{ Inspyril Turbuhaler } \\
\hline & Mean (SD) & Range & Mean (SD) & Range \\
\hline Total emitted dose (\% label claim) & $83.5(13.9)^{*}$ & $25.7-96.5$ & $72.5(11.1)$ & $41.3-88.8$ \\
\hline Total emitted dose $(\mu \mathrm{g})$ & $167.1(27.8)^{*}$ & $51.3-193.0$ & $72.5(11.1)$ & $41.3-88.8$ \\
\hline Fine particle mass ( $\%$ label claim) & $36.8(9.8)^{*}$ & $1.2-46.1$ & $28.7(7.7)$ & $5.1-38.2$ \\
\hline Fine particle mass (\% TED) & $42.7(9.4)$ & $4.7-51.3$ & $39.4(9.4)$ & $10.5-50.0$ \\
\hline Fine particle mass $(\mu \mathrm{g})$ & $73.7(19.5)^{*}$ & $2.4-92.2$ & $28.7(7.7)$ & $5.1-38.2$ \\
\hline
\end{tabular}
delivered dose and particle size distribution of Diskus and Turbuhaler in asthma and COPD patients using real-life patient inhalation profiles. Inhalation profiles of these patients with a wide range of bronchial obstruction and inspiratory muscle function were replayed through the Electronic Lung: a computer-driven inhalation ma-

Table 3. Electronic Lung Results

Total emitted dose as percentage of label claim; fine particle Mass as percentage of label claim and as percentage of the total emitted dose. ${ }^{*} p<0.05$ differences between Diskus and Turbuhaler. 


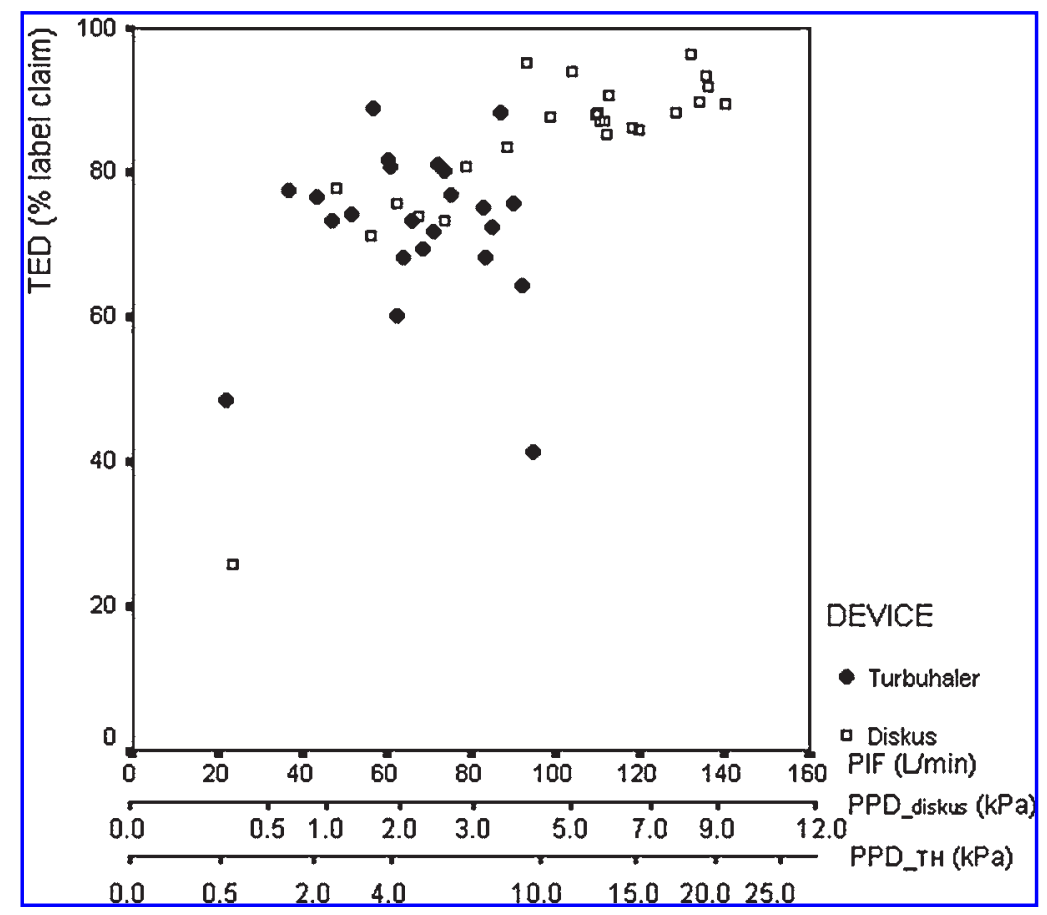

FIG. 2. The relationship between the total emitted dose (TED) as percentage of label claim and peak inspiratory flow (L/min). The relationship between TED and peak pressure drop (PPD; kPa) of Diskus and Turbuhaler were also shown.

noeuvre simulator. Conventional cascade impactors operate at constant flows, which is an unrealistic deviation from the actual flow patterns with respect to the drug release from the device. The airflow through a device during a patient's inhalation not only varies with time, but also between inhalations and patients. The Electronic Lung realistically simulates drug delivery, with real flow patterns.

The selected inhalation profiles for this in vitro comparison of Diskus and Turbuhaler showed significant lower PIF values and higher inhalation times for Turbuhaler. This was due to the different resistivities (resistance to airflow) of both devices. PIF decreases with increasing resistivity, ${ }^{17}$ which subsequently increases the total inhalation time. ${ }^{18}$

An appropriate and clinically efficient DPI should deliver a reliable, consistent dose and a large FPM, relatively independent of flow. The latter should possibly be generated with relatively low inspiratory pressures. In general, the TED for Inspyril Turbuhaler appeared to be significantly lower than that for Ventolin Diskus. This may be due to the fact that the PIF measurements were lower for Turbuhaler.

The present study showed that the TED_diskus is affected by PIF and is mainly due to one very low result. Three relatively low TED_turbuhaler results did not fit well with a linear regression. There was also an indication that the dependency of TED on PIF of both devices was more marked at lower flows.

The relatively high variability of TED for Ventolin Diskus appeared to be a result of one low result. This suggests that the variation in drug particle release may decrease with increasing effort. After fitting separate regression models for each device, the residual variability for Ventolin Diskus was less than that for Inspyril Turbuhaler. This means that the Diskus provided a more consistent dose delivery.

The flow-dependent drug output (TED), consistency of the dose, and number of particles in the respirable range (FPM) may theoretically lead to a decreased clinical efficacy in patients who are not able to generate an adequate flow through Diskus or Turbuhaler.

Both devices were extensively studied, both in vitro and in vivo. Our data confirmed the results of two other studies, which found that a higher FPM of Fluticasone Diskus was delivered at 60 $\mathrm{L} / \mathrm{min}$ as compared to $30 \mathrm{~L} / \mathrm{min} \cdot{ }^{19,20}$ Also, other in vitro device evaluations showed that the TED and FPM of the Turbuhaler increase at higher PIF. ${ }^{11,20-22}$ However, in contrast to our results, a 


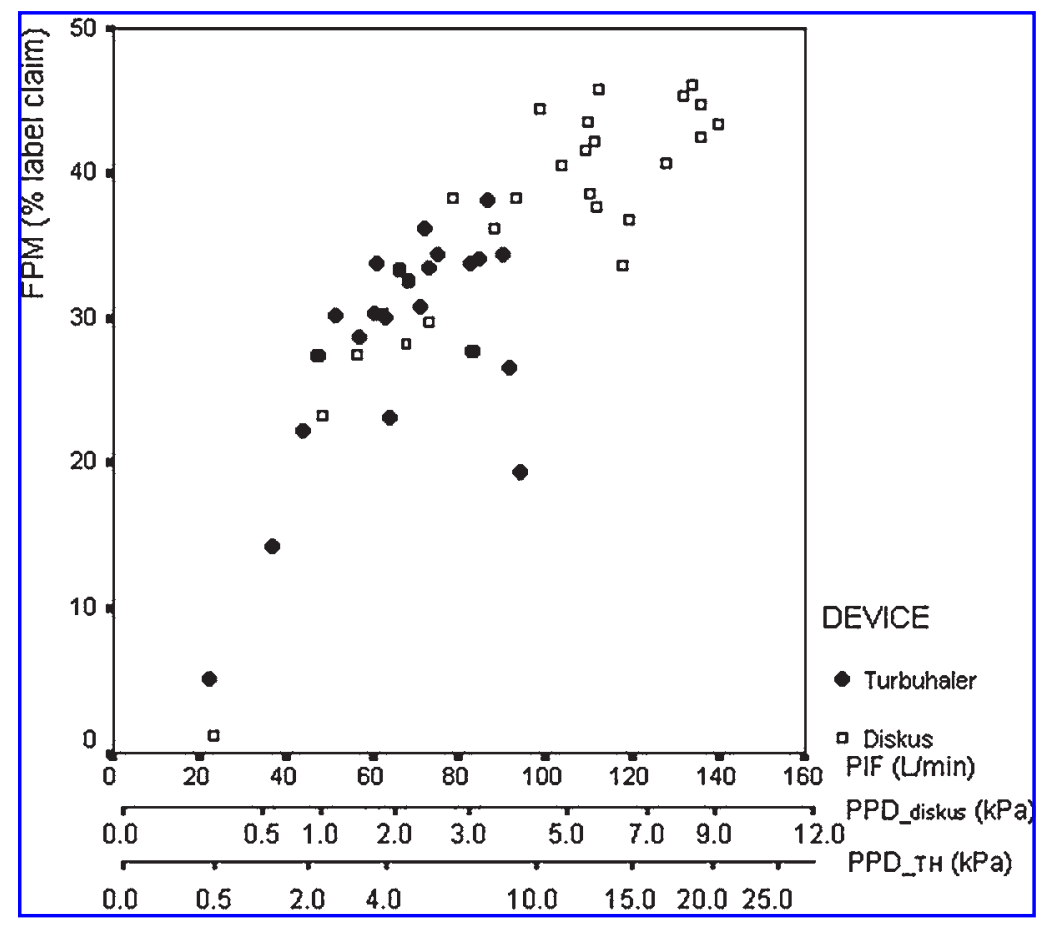

FIG. 3. The relationship between the fine particle mass (FPM) as percentage of label claim and peak inspiratory flow (L/min). The relationship between FPM and peak pressure drop (PPD; kPa) of Diskus and Turbuhaler were also shown.

consistent dose delivery and FPM, relatively independent of flow was described by several studies for Diskus. ${ }^{23,24}$ Since dose emission properties are specific for each drug-device product and the results of this study are only applicable for Ventolin Diskus and Inspiryl Turbuhaler, the conclusions may not be extrapolated for the different combinations. Another important reason for variation may be attributed to the unrealistic test conditions in those studies, that only used a fixed flow Cascade Impactor. Nevertheless, this was not the first study using the Electronic Lung methodology. Several studies used the Electronic lung methodology rather than a fixed flow rate cascade impactor, which all demonstrate that dose delivery from the Diskus is independent of flow. ${ }^{11,25}$ The reason that our data seem to contradict these studies could be that the data chosen for our evaluation was in the range of $21 / 25$ the extremes of the 1500 inhalation profiles collected for each device. Only 4/25 were selected from the middle range. This resulted in a population of inhalation profiles which included not only profiles of the usual outpatient population but also the real outliers from patients at the extremes of disease severity. These profiles were also acquired from severely exacerbated patients to whom a Diskus or Turbuhaler would normally not have been prescribed. So, the low profiles for Diskus and Turbuhaler were lower than collected in other studies. Recalculations of the fit without the lowest flows (PIF_diskus $23 \mathrm{~L} / \mathrm{min}$ and PIF_turbuhaler $22 \mathrm{~L} / \mathrm{min}$ ) were performed and there was evidence that these outliers influenced the overall results of TED. For TED turbuhaler the slope was actually negative when the low flow data were removed. This was presumably influenced by the lowest TED result belonging to the highest PIF. The regression models for FPM (\%label claim) with and without the low flow data were also calculated, but there was no evidence that the model parameters change when the low flow data were omitted.

This study demonstrated that in practice, different devices are not operating at corresponding flows by patients. Patients are only able to generate a certain (maximal) inspiratory effort (pressure) irrespective of which inhaler they inhale through. The inherent resistivity of the given device will determine the flow achieved through the device (Figs. 2 and 3). Comparison of the performance of inhalation devices with different resistivities at the same PIF must be considered carefully, since a particular flow may relate to an 
entirely different inspiratory effort in each device. Conventional in vitro measurements were usually performed with constant fixed flows of 30, 60 and $90 \mathrm{~L} / \mathrm{min}$. Nevertheless, the majority of patients inhaled with higher PIFs through the Diskus. So, the in vitro results in the PIF range 30-90 L/ min are of high clinical relevance for Turbuhaler, but less for Diskus. Since the PIF is in general achieved after the release of the powder, the slope of the pressure profile (in $\mathrm{kPa} / \mathrm{sec}$ ) was also described as an important variable. ${ }^{5,6,11,26}$ Surprisingly, in the present study PIF seemed to influence the Electronic Lung results. There was no indication of a significant relationship with the other inhalation profile variables. However, it was shown for Diskus and Turbuhaler that peak inspiratory flow and slope correlate well in a wide range of patient groups. ${ }^{27}$

In conclusion, the TED and FPM of Diskus and FPM of Turbuhaler for the salbutamol product were affected by PIF, the flow-dependency being greater at low PIF ( $<40 \mathrm{~L} / \mathrm{min})$. Lower PIFs occurred more often when using Turbuhaler than Diskus. Dose to patient (TED), dose consistency, and the mass of particles in the respirable range were higher for Diskus as compared to Turbuhaler. In vitro studies with a constant flow or with real-life flow profiles yield different results.

The flow dependency of TED and FPM of Diskus do not agree with other data published. This is likely to be due to the use of IPs, which include not only the usual clinical population but also the real outliers.

\section{ACKNOWLEDGMENTS}

We acknowledge the statistical support of M. Davies (GlaxoSmithKline R\&D, Ware). This study was supported by GlaxoSmithKline Zeist, The Netherlands.

\section{REFERENCES}

1. Pauwels, R., Newman, S., and Borgstrom, L. 1997. Airway deposition and airway effects of antiasthma drugs delivered from metered-dose inhalers. Eur. Respir. I. 10:2127-2138.

2. Dolovich, M.A. 2000. Influence of inspiratory flow rate, particle size, and airway caliber on aerosolized drug delivery to the lung. Respir. Care 45:597-608.

3. Clark, A.R., and Hollingworth, A.M. 1993. The relationship between powder inhaler resistance and peak inspiratory conditions in healthy volunteers-implications for in vitro testing. L. Aerosol Med. 1993;6: 99-110.

4. Hawksworth, G.M., James, L., and Chrystyn, H. 2000. Characterization of the inspiratory manoeuvre when astmatics inhale through a Turbohaler pre- and postcounselling in a community pharmacy. Respir. Med. 94:501-504.

5. Everard, M.L., Devadason, S.G., and Le Souef, P.N. 1997. Flow early in the inspiratory manoeuvre affects the aerosol particle size distribution from a Turbuhaler. Respir. Med. 91:624-628.

6. de Boer, A.H., Winter, H.M.I., and Lerk, C.F. 1996. Inhalation characteristics and their effects on in vitro drug delivery from dry powder inhalers. Part 1. Inhalation characteristics, work of breathing and volunteers'preference in dependence of the inhaler resistance. Int. J. Pharm. 130:231-244.

7. Carveth, H.C., and Kanner, R.E. 1999. Optimizing deposition of aerosolized drug in the lung: a review. Medscape Respir. Care 3.

8. de Boer, A.H., Gjaltema, D., and Hagedoorn, P. 1996. Inhalation characteristics and their effects on in vitro drug delivery from dry powder inhalers. Part 2. Effect of peak flow rate (PIFR) and inspiration time on the in vitro drug release from three different types of commercial dry powder inhalers. Int. I. Pharm. 138: 45-56.

9. Sciarra, J. 1966. International Encyclopaedia of Pressurized Packaging (Aerosols). Pergamon Press, New York.

10. Burnell, P.K.P., Malton, A., Reavill, K., et al. 1998. Design, validation and initial testing of the electronic lung device. L. Aerosol Sci. 29:1011-1025.

11. Bisgaard, H., Klug, B., Sumby, B.S., et al. 1998. Fine particle mass from the Diskus inhaler and Turbuhaler inhaler in children with asthma. Eur. Respir. I. 11: 1111-1115.

12. Broeders, M.E., Molema, J., Hop, W.C., et al. 2003. Inhalation profiles in asthmatics and COPD patients: reproducibility and effect of instruction. I. Aerosol Med. 16:131-141.

13. Broeders, M.E., Molema, J., and Folgering, H.T. 2002. Do asthma and COPD patients adequately inhale their medication during acute exacerbation. Am. J. Respir. Crit. Care Med. 165:B7.

14. Brindley, A., Sumby, B.S., and Smith, I.J. 1994. The characterisation of inhalation devices by an inhalation simulator: the electronic lung. I. Aerosol Med. 7:197200.

15. Broeders, M.E., Molema, J., and Folgering, H.T. 2001. Resistivities of placebo and active Diskus inhalers compared. Int. I. Pharm. 228:219-222.

16. Burnell, P.K., Malton, A., Reavill, K., et al. 1998. Design, validation and initial testing of the electronic lung device. I. Aerosol Sci. 29:1011-1025.

17. Chavan, V., and Dalby, R. 2000. Effect of rise in simulated inspiratory flow rate and carrier particle size on powder emptying from dry powder inhalers. AAPS Pharm. Sci. 2:E10. 
18. de Koning, J.P., van der Mark, T.W., Coenegracht, P.M.J., et al. 2002. Effect of an external resistance to airflow on the inspiratory flow curve. Int. J. Pharm. 234:257-266.

19. Fuller, R. 1995. The Diskus: a new multi-dose powder device-efficacy and comparison with Turbuhaler. L. Aerosol Med. 8(Suppl 2):S11-S17.

20. Davies, N., Feddah, M., Brown, K., et al. 2000. In-vitro characterisation of metered dose inhaler versus dry powder inhaler glucocorticoid products: influence of inspiratory flow rates. J. Pharm Pharmac. Sci. 3:317324.

21. Hill, L.S., and Slater, A.L. 1998. A comparison of the performance of two modern multidose dry powder asthma inhalers. Respir. Med. 92:105-110.

22. Malton, A., Sumby, B.S., and Smith, I.J. 1995. A comparison of in vitro drug delivery from two multidose powder inhalation devices. Eur. J. Clin. Res. 7:177-193.

23. Prime, D., Grant, A.C., Slater, A.L., et al. 1999. A critical comparison of the dose delivery characteristics of four alternative inhalation devices delivering salbutamol: pressurized metered dose inhaler, Diskus inhaler, Diskhaler inhaler, and Turbuhaler inhaler. $L$. Aerosol Med. 12:75-84.

24. Kamin, W.E., Genz, T., Roeder, S., et al. 2002. Mass output and particle size distribution of glucocorticosteroids emitted from different inhalation devices depending on various inspiratory parameters. $\underline{\text {. Aerosol. }}$ Med. 15:65-73.

25. Burnell, P.K., Small, T., Doig, S., et al. 2001. Ex vivo product performance of Diskus and Turbuhaler inhalers using inhalation profiles from patients with se- vere chronic obstructive pulmonary disease. Respir. Med. 95:324-330.

26. de Boer, A.H., Bolhuis, G.K., Gjaltema, D., et al. 1997. Inhalation characteristics and their effects on in vitro drug delivery from dry powder inhalers. Part 3. The effect of flow increase rate (FIR) on the in vitro drug release from the Pulmicort 200 Turbuhaler. Int. I. Pharm. 153:67-77.

27. Broeders, M.E., Molema, J., Vermue, N.A., et al. 2001. Peak Inspiratory Flow Rate and slope of the inhalation profiles in Dry Powder Inhalers. Eur. Respir. I. 780-783.

Received on January 12, 2004 in final form, September 9, 2004

Reviewed by:

Myrna B. Dolovich, P.Eng. Paula J. Anderson, M.D.

Address reprint requests to: Dr. M.E.A.C. Broeders

Department of Pulmonary Diseases Dekkerswald University of Nijmegen P.O. Box 66

6560 AB, Groesbeek, The Netherlands

E-mail:m.broeders@zonnet.nl 
This article has been cited by:

1. John Haughney, David Price, Neil C. Barnes, J. Christian Virchow, Nicolas Roche, Henry Chrystyn. 2010. Choosing inhaler devices for people with asthma: Current knowledge and outstanding research needs. Respiratory Medicine 104:9, 1237-1245. [CrossRef]

2. Susan Hoe, Daniela Traini, Hak-Kim Chan, Paul M. Young. 2009. Measuring charge and mass distributions in dry powder inhalers using the electrical Next Generation Impactor (eNGI). European Journal of Pharmaceutical Sciences 38:2, 88-94. [CrossRef]

3. D. S. Wilson, M. S. Gillion, P. J. Rees. 2007. Use of dry powder inhalers in COPD. International Journal of Clinical Practice 61:12, 2005-2008. [CrossRef]

4. H.A. Tiddens, D.E. Geller, P. Challoner, R.J. Speirs, K.C. Kesser, S.E. Overbeek, D. Humble, S.B. Shrewsbury, T.A. Standaert. 2006. Effect of Dry Powder Inhaler Resistance on the Inspiratory Flow Rates and Volumes of Cystic Fibrosis Patients of Six Years and Older. Journal of Aerosol Medicine 19:4, 456-465. [Abstract] [Full Text PDF] [Full Text PDF with Links] 